ARTICLE

\title{
The Diversity of Capitalism and Heterogeneity of Firms-A Case Study of Japan during the Lost Decade
}

\section{Sébastien LECHEVALIER*}

EHESS, 54, boulevard Raspail, 75006, Paris, France and Maison Franco-Japonaise, 3-9-25, Ebisu, Shibuya-ku, Tokyo 150-0013, Japan.

E-mail: sebastien.lechevalier@ehess.fr

\begin{abstract}
Most institutional theories of the diversity of capitalism (at least implicitly) assume the existence of a representative firm in each type of capitalism. Based on a case study of Japan during the Lost Decade (1992-2005), this paper aims at showing that this assumption introduces severe drawbacks in the analysis of Japanese capitalism in crisis. After having proposed a survey of theories of Japanese capitalism and of its crisis, we assess the increasing heterogeneity of Japanese firms since the beginning of the 1990s, in terms of performances and "models", and propose some explanations of this increasing heterogeneity, which concerns firms of similar size and belonging to the same sectors. We then propose an alternative interpretation of this crisis - the lack of coordination of an increasing heterogeneity-and argue that it requires a new characterization of Japanese capitalism. In the final part, we extend our analysis beyond the Japanese case in arguing that our framework, which is based on an alternative theory of the firm, on the study of the evolution of the heterogeneity of organizations, and on the analysis of aggregation and coordination of the micro behaviors through institutions, provides a more dynamic understanding of institutional change.
\end{abstract}

Keywords: Japanese capitalism, heterogeneity of firms, coordination, institutional change, organizational change.

\section{Introduction}

The period 1991-2005 in Japan has deservedly been given the title of the "Lost Decade," as the astonishing performances of the Japanese economy have been in sharp contrast with those of the preceding period, when many analysts predicted that Japan would become the Number One economy in the world in the 1990s. At the same time, Toyota,

JEL: B52, D24, L16, L22, P16, P51.

*The author is grateful to Robert Boyer, Donatella Gatti, Bruno Amable, Hideaki Miyajima, Akinori Isogai \& Hiroyasu Uemura for their helpful comments. 
the company which has been considered by many authors as the most representative of the specificities of Japanese capitalism at the firm level and has been the object of innumerable studies, did not experience any major crisis. Even better, from the second half of the 1990s, every year, Toyota has dramatically increased its sales and reached a record high profit, before becoming finally the world number one car maker, in overtaking Ford and then General Motors in 2007. Therefore, the contrast between the trajectories of the Japanese economy and its leading company since the beginning of the 1990 s is striking.

One possible explanation of this paradox is that Toyota may have changed completely its model (for example, because of its internationalization) and is no more representative of the typical Japanese firm. This explanation is not satisfying. It is true that Toyota's organization has changed over the past decade but there is nothing new in this, as it is possible to define the Toyota model by its ability to evolve (and expectedly to improve) permanently (Fujimoto, 1999). Yet, Toyota did not change its basic principles of organization and its core social compromise during this period, contrary to other firms. It is worth considering that it has been rather "conservative" from this point of view. Moreover, we are exemplifying here the case of Toyota because of its fame, but it is far from being unique. For example, a company like Canon, which shares with Toyota many of the characteristics of the so-called J-firm model, has been particularly successful during the Lost Decade, without giving up its major principles of organization. What is paradoxical is not that during a macro-structural crisis some firms operating in specific sectors continue to be successful. It is the fact that what is presented as the limits of the model at the macro level seems to be precisely the basis of the strength of some companies.

Another extreme explanation of the contrasted trajectories of a leading company like Toyota and the Japanese economy as a whole is that theories of Japanese capitalism have been mistaken so far in confusing a model of capitalism and one company's organization. Again, this explanation is much too simplistic: none of the theories of Japanese capitalism we survey in this paper has confused one particular firm and the national economy. However, in a more subtle way, it is true that most of them have assumed the existence of a representative firm within a national form of capitalism, while focusing on the variety of the national forms of capitalism. In this paper, we argue that this hypothesis introduces severe drawback in the understanding of Japanese capitalism, its crisis, and its current transformation.

This first paradox is directly linked to a second one, which has not yet been 
satisfactorily explained. The questions addressed by various authors (among others, Yamamura and Streeck, 2003; Vogel, 2006; Witt, 2006) have not concerned the causes of the crisis by themselves but rather the change or the absence of change of the model. Basically, the investigation of institutional change in Japan has led to a micro-macro paradox: at the macro level the changes seem to have been very slow, if not inexistent, while, at the micro level, drastic changes appear to have been numerous. One of the most famous (but far from being the only one) was the alliance between Renault and Nissan in 1999, and the drastic change of management that followed. One may argue that one should not confuse institutional change, which takes place at the aggregate level, and organizational change, which takes place at the micro level (Witt, 2006). However, not taking into account the changes at the micro level leads to an overestimation of institutional inertia. Therefore, this paper should be read as an attempt among others (e.g. Streeck and Thelen, 2005; Deeg and Jackson, 2006) to provide a more dynamic analysis of institutional change.

In this paper, we try to explain these two linked paradoxes - the micro-macro paradox and the contrasted performances of the national economy and of firms, which have been considered as the most representative of the so-called Japanese model of capitalism. First, we argue that the diverse trajectories of Toyota and Nissan are symbolic of what we label the "increasing heterogeneity of Japanese firms," a phenomenon which has been very little studied so far. ${ }^{1)}$ This increasing heterogeneity concerns both the performances and the underlying models (i.e., organizations and strategies) of Japanese companies. Furthermore, it concerns firms of similar size and within the same industry. Second, this trend is essential to understand the current changes of the Japanese capitalism. It is also a part of the explanation of the duration of its crisis: we propose an interpretation of this crisis as a lack of coordination of the increasing heterogeneity of Japanese firms. This thesis is in sharp contrast with previous interpretations, focusing on the lack of diversity (Aoki, 2000) or the excessive coordination within Japanese capitalism, impeding any social change (Witt, 2006).

After having briefly surveyed some theories of Japanese capitalism and their explanation of its crisis and shown that they basically share the assumption of the representative firm within a national variety of capitalism, we assess the increasing heterogeneity of Japanese firms since the beginning of the 1990s beyond the simple example we gave in this introduction, and we propose our own interpretation by introducing the concept of coordination. Finally, we generalize our framework beyond

${ }^{1)}$ Exceptions are Yamamura and Streeck (2003), Vogel (2006), and more recently Aoki et al. (2007). 
the Japanese case and argue that our framework is a contribution to a more dynamic analysis of institutional change.

\section{Back to Theories of Japanese Capitalism and of Its Crisis}

\subsection{Theories of the $\mathrm{J}$ model}

The performance of the Japanese economy until the beginning of the 1990s gave birth to competing theories of the so-called Japanese model. Despite their differences, they share the idea that this model can be characterized by a representative firm. This is for example the case of the Régulation theory (Boyer and Yamada, 2000) and of the "variety of capitalism" (VOC) approach (Hall and Soskice, 2001). ${ }^{2)}$

This is also the case with the most influential theory of the Japanese model, the one developed by Aoki (1986, 1989, 1990, and 2000). It does not mention the concept of capitalism and focus on the organization of the firm as the main characteristic of the model. The starting point of this theory is the recognition that firms are information systems. The organizational schemes differ, depending on how these information processing activities are structured within the firm. In the vintage version of this theory, two information structures-a vertical one and a horizontal one-are distinguished (Aoki, 1986). The first one is characteristic of the A-firm, while the second one is characteristic of the J-firm. Further versions of the theory have taken into account the historical evolution of each information structure and therefore of each organizational mode within each country: functional hierarchy and decentralized hierarchy on the one hand, and homogenous team and horizontal hierarchy in the other hand (e.g. Aoki, 2000). Each model has a comparative advantage in particular industries. For example, the horizontal hierarchy fits well to the requirements of the car industry, while the functional hierarchy has evolved towards decentralized hierarchy in the software industry. However, for historical and institutional reasons, each is prevalent in a given country. There is therefore a tendency towards homogeneous organizations across countries, even if it would be more efficient to have diverse modes of organization in each country. That is why it is possible to characterize the Japanese economy as a whole by one predominant model of firm. Moreover, this model is characterized by complementarities between employment contracts and financial contracts, both long-

\footnotetext{
${ }^{2)}$ For a discussion of these two approaches, see Lechevalier (2007). It is worth noting that some regulationists have contributed to the approach in terms of "productive models," emphasizing the heterogeneity of firms in the car industry (Freyssenet et al., 1998). However, for a number of reasons, these two approaches have never been connected.
} 
term oriented, by opposition to what is observed in the A model, which is short-term oriented (Aoki, 1989). These complementarities reinforce the homogeneity of the model within the boundaries of the national economy.

\subsection{Theories of Japanese capitalism in crisis}

Most theories of the Japanese model can be considered as answers to the common belief in the 1980s and the 1990s about the convergence towards a single model of capitalism, that being the Japanese model in the 1980s or the American model in the 1990s. Their contribution has been to show the fundamental diversity of capitalism, and, in particular, to prove that Japanese capitalism is not a variant of American capitalism. As we have seen, doing so despite their fundamental differences, they have (at least implicitly) assumed the existence of a representative firm within each national model of capitalism. We argue here that, if this working hypothesis is acceptable when the purpose is to underline the cross-sectional diversity of capitalism, it is misleading when the goal is to analyze the evolution over time of one given national model. This is particularly the case when the research agenda includes an explanation of the form of the Japanese crisis and of its unusual duration, which are both particularly challenging issues. ${ }^{3)}$

In fact, in most analyses of the Japanese crisis, the assessment of social change (or of its absence) and the explanation of the crisis are interrelated. For example, according to Witt (2006): 1) Japanese capitalism did not change drastically during the Lost Decade (despite favourable circumstances, its dismal economic performance) because of 2) the strong societal coordination and of 3 ) the weak pressure from the micro level (basically autonomous and apolitical action that is not aimed at institutional change at the system level, but at providing relief from institutional misalignment at the micro level). ${ }^{4)}$ To understand how these results emerge, it is necessary to specify the distinction proposed by the author between two types of adjustment. One is societally coordinated in the sense that it involves the cooperation of a number of actors toward changing institution; these actors are operating at the aggregate level. The other one is autonomous: it occurs when actors introduce institutional innovations without involving active societal coordination, cooperation, or bargaining, typically through nonconformity with the informal institutional structure; these actions usually take place at the micro level; in this case, a subsequent diffusion of institutional innovation occurs through evolutionary and isomorphic processes. The latter is most popular in Liberal Market Economies (LMEs),

\footnotetext{
${ }^{3)}$ We do not discuss here the causes of the crisis, whose analysis is characterized by a (relative) consensus focusing on its financial origin.

4) This diagnosis of institutional inertia is shared by the Régulation theory (Boyer and Yamada, 2000).
} 
while the former is the most common in Coordinated Market Economies (CMEs), including Japan, where it has not been effective. To put it simply, according to Witt, the duration of the Japanese crisis is explained by an excess of coordination.

Analyzing the impediments to recovery is an alternative way to understand the duration of the crisis. According to Aoki (2000), the main impediment for the Japanese economy to experience a new growth regime based on the development of the technologies of information and communication and on their use within the firm lies in the lack of organizational diversity. More precisely, Aoki refers here to what he considers as one of the major specificities of Japanese capitalism, the so-called "bureaupluralism" which can be defined as follows: the mechanisms through which the vested interests of all parties are equally protected through the mediation of the bureaucracy. During the high-growth period, the bureaucracy played an important and positive role as agent and arbitrator in protecting the vested interests of pluralistic groups in different fields, and of redistributing the rents throughout the whole economy.5 However, bureaupluralism is fundamentally detrimental to organizational diversity because it perturbs the Darwinian process in each industry. That is why Aoki calls for an institutional reform that allows new organizational modes to be experimented with and implemented in industries where the conventional assimilated structure is inefficient. ${ }^{6}$ )

To sum-up, two basic ideas emerge from the joint analysis of the crisis and of the institutional change: the excess of coordination (Witt, 2006) and the lack of diversity (Aoki, 2000). The starting point of our own interpretation of the crisis of Japanese capitalism is a departure from these two last results.

\footnotetext{
${ }^{5)}$ This aspect will be analyzed as a "coordination" device in our own framework.

${ }^{6}$ To be fair, it is worth noting that in a very recent book, Aoki and his co-authors have revised this analysis in providing the first systematic investigation on the increasing heterogeneity of firms in the specific field of corporate governance (Aoki et al., 2007). First, they recognize that no clear single pattern has emerged and we can characterize the current situation by the coexistence of three models, the traditional $\mathbf{J}$ model, the hybrid model, characterized by market finance and greater relational orientation in term of internal characteristics, and the inverse hybrid model (relational finance with more market oriented employment and incentive pattern). Second, they suggest that diversity may remain a defining feature of Japanese corporate governance. It implies that this analysis potentially overcomes the limitation, which has been underlined until now, the hypothesis of a representative model in each national form of capitalism. In our opinion, this is only a potential at this stage, because the analysis needs to be more theoretically grounded and generalized to other dimensions of the organization of firms beyond the case of corporate governance.
} 


\section{The Japanese Crisis as a Lack of Coordination of an Increasing Heterogeneity}

\subsection{Assessing the increasing heterogeneity of Japanese firms during the Lost Decade ${ }^{7)}$}

\subsubsection{The increasing heterogeneity of performances and models}

Studies at the micro level on productivity (Fukao and Kwon, 2006; Ito and Lechevalier, 2007) and on profitability (Nakamura, 2002) give converging evidence on increasing dispersion across companies since the mid-1990s. Moreover, it concerns firms of similar size and within narrowly defined industries.

This increasing heterogeneity concerns also the forms of organization and strategies. Because of the lack of space, we give here evidence regarding only human resource management and corporate finance. However, the same applies for other dimensions of the organization of firms. The common picture regarding the HRM is that the Japanese firms are moving away from the "traditional" practices of long term employment, seniority wages, and enterprise-based unions. However, regarding long term employment, Hurlin and Lechevalier (2003) show that the speed of adjustment is very stable on average between the 1970s and the 1990s. Yet the standard deviation of the individual speeds is increasing. It shows an increasing heterogeneity of HRM practices between the 1970s and the 1990s. Moreover, the authors find that the foreign owner ratio and the link with the main bank have respectively positive and negative impacts in the 1990s, while the size is no longer significant. As for corporate finance and governance, the changes have been drastic since the beginning of the 1990s. However, they do not constitute a uniform switch towards the Anglo-Saxon models, but rather an increasing heterogeneity of the practices (Aoki et al., 2007). For example, in spite of the deregulation of the bond market in the mid-1980s, the overall dependence of firms on bank borrowing increased. Large firms lessened their ties with banks and began financing through bonds, but smaller listed firms continued borrowing from banks. In sum, size matters from this point of view. But this is not the only determinant: firms with already high levels of bank debt relied on their main bank for an increasing proportion of those loans.

This growing diversity for each element of the firms' organization and strategy makes it particularly difficult to define the competing "models". They should be characterized by a certain coherence, which can basically be found in the complementarities between

\footnotetext{
${ }^{7)}$ For a more complete assessment of the increasing heterogeneity of firms since the beginning of the 1990s, see Lechevalier (2007).
} 
the different elements of the strategy (e.g., HRM and corporate governance). However, some of the most recent empirical analyses have shown that these complementarities are less clear than they used to be, or to be thought (Aoki et al., 2007). It has led these analyses to develop the concept of hybridization. ${ }^{8}$ ) We argue here that the emergence of hybrid models, whose characteristics are in contradiction with the postulates of the theory of institutional complementarities, shows their limits and should lead to a revision of the underlying theory of the firm. In this context, it is important to develop accurate theoretical and empirical tools to analyze this extended form of complementarities. From an empirical point of view, a practical and rigorous way to define the models by taking into account various complementarities is to use a cluster analysis, as done by Miyajima in Aoki et al. (2007) or by Ito and Lechevalier (2007). This methodology is helpful in defining a hierarchy among the five dimensions of the firms' strategy, in the line with the concept of institutional hierarchy developed by Amable (2003).

\subsubsection{How can the increasing heterogeneity of Japanese firms be explained?}

The mainstream explanation of the heterogeneity of firms is that its evolution is technology-driven. This is confirmed in the case of Japan: the TFP gap is widening in the industries where R\&D intensity is high (Fukao and Kwon, 2006). The internationalization of the Japanese economy seems to have had a similar effect: the most productive firms have a higher probability of entering the international market (either through exports or FDI); in return, both exports and FDI do improve productivity after a while (Kimura and Kiyota, 2006). To sum up, it is possible to conclude that "similar to the IT divide among workers, a new divide caused by R\&D and internationalization seems to be emerging and growing in Japan's manufacturing industry" (Fukao and Kwon, 2006).

Business cycles are another determinant of the evolution of the heterogeneity of firms. From a Darwinian or Schumpeterian perspective, the natural selection mechanism in a market economy, particularly active during recessions, leads to the survival of the best firms and the death (or exit) of the least performing ones and therefore to a greater homogeneity (Aghion and Saint-Paul, 1994). However, does this mechanism hold in severe recessions, like the one that Japan experienced in the second half of the 1990s? The answer is negative: relatively efficient firms in terms of TFP went out of business while relatively inefficient ones survived during the banking crisis of 1996-1997 (Nishimura et al., 2005). It produced de facto an increasing heterogeneity of

\footnotetext{
${ }^{8)}$ See note 6.
} 
performance by firms.

If one turns to more institutional explanations, one should first mention the fact that the growing heterogeneity of the corporate governance of Japanese firms is basically explained by the fact that not all firms are equally exposed to pressure for change and that existing institutions also constrain change along particular trajectories (Aoki et al., 2007). For example, foreign investors concentrate in some firms and this has a strong impact on their corporate governance: firms with higher levels of foreign ownership are more likely to adopt "Anglo-American" style corporate reforms or modes of restructuring. The result is clearly a growing heterogeneity among Japanese firms. Another reason is relative to the specific form of some reforms in Japan, resulting from a compromise between different actors, as in the case of the reform of the board of directors, which can be characterized by its "enabling" nature (Jackson in Aoki et al., 2007).

Our own working hypothesis is that financial deregulation was the origin of the increasing heterogeneity. What was observed in Japan in the 1980s-1990s is similar to what gave birth to the so-called dual structure of the Japanese economy in the 1950s. Whereas the origin of this latter one is to be found in the differentiated introduction of foreign technology in Japanese firms according to their size in the interwar period (Kiyota and Okazaki, 2005), the origin of the currently observed increasing heterogeneity of Japanese firms has to be found in the financing deregulation since the 1980s, which broadened the scope of choices that firms were facing in term of financing. If this hypothesis is true, it means that characterization of the different "models" can be achieved based on analysis of their financial structure in relation to the other dimensions of the firms' organization and strategy.

\subsection{The Japanese crisis as a lack of coordination}

The simultaneity of the Japanese crisis and of the increasing heterogeneity of the Japanese firm is striking. We argue that the difficulty of explaining the Japanese crisis in existing theoretical frameworks comes from a misleading aggregation of micro behaviors and performances and, therefore, an incomplete understanding of the processes of organizational and institutional changes. ${ }^{9)}$ To solve this problem, we introduce the concept of coordination, which allows a richer understanding of the interactions between the micro and the macro levels. In this section, we consider this concept from the point of view of the concrete institutions of Japanese capitalism, before

\footnotetext{
${ }^{9}$ We are concerned here not with the causes of the crisis, but rather with its duration and its form (stagnation rather than depression).
} 
specifying it from a more theoretical point of view in the final part.

\subsubsection{Introducing the "lack of coordination" view of the Japanese crisis}

To understand the nature of our interpretation of the Japanese crisis and the role that the concept of coordination plays, it is practical to contrast it with the interpretations proposed by Witt (2006) and Aoki (2000), which have been presented in the first part of this paper. By opposition to these analyses, our interpretation can be summarized as follows: 1) On average, apparently, the system is stable, but at the micro level it changed drastically through an increasing heterogeneity of the performance of firms, and of their organization and strategies (which eventually takes the form of a polarization); 2) The Japanese crisis - its intensity and its length-is not explained by a lack of institutional change but by disruptions in the former order, and structural incompatibilities between the previous system, international pressures, and its reform by inside forces, which lead to a lack of coherence and of coordination at the macro level. If we put together the two propositions above, we can summarize our interpretation of the Japanese crisis as follows: in our framework, the duration and the form of the Japanese crisis are explained by a lack of coordination of the increasing heterogeneity of Japanese firms.

\subsubsection{The "Golden age" of coordination in the Japanese economy}

The presentation of the "lack of coordination" view of the Japanese crisis preliminarily requires an explanation and a specification of the coordination in the former model of Japanese capitalism. We refer to this period - which corresponds to the high growth and to the successful adjustments of the 1970s - as the "Golden Age" of coordination in the Japanese economy. It is possible to distinguish between three forms of coordination during this period.

First, the coordination at the group level is well-known (Streeck and Yamamura, 2001). It concerns specifically the keiretsu structure, whose impact in term of R\&D spillovers has been particularly emphasized (Suzuki, 1993), and the sub-contracting system, which has been recognized as a device to share uncertainty and increase flexibility (Nishiguchi, 1994). Regarding the keiretsu structure, its contribution has been described as follows: the keiretsu structure contributed to reduce ex post the heterogeneity of the performance of its members; the groups act to maintain balance in their ranks and ensure the survival of all members by supporting the weak members at the expense of the strong members (Lincoln and Gerlach, 2004). As for the subcontracting structure, a long tradition-the so-called dualist theory-has analyzed it from the point of view of exploitation. If it is true that significant differentials exist between the subcontractors and the subcontracting company, it should be emphasized 
that the subcontracting relationship in Japan developed in the postwar period because of its economic gains: through subcontracting, Japanese firms developed inter-firm problem-solving mechanisms to achieve low costs and high quality products. This attribute of the Japanese way of subcontracting - which can be qualified as coordination oriented-is in sharp contrast with practices in the UK (even in the same industries), which are more bargaining-oriented and less efficient (Nishiguchi, 1994).

Second, the coordination device at the industry level has tended to be forgotten by some comparative analyses of Japanese capitalism. However, the shunto, as a coordinated bargaining process, played this role, especially in the 1960s and 1970s. It contributed greatly to the distribution of productivity gains across sectors and to the absence of inflation (Boyer and Yamada, 2000). More precisely, four characteristics of shunto made it an essential coordination device (Sako, 2006): 1) The initiative of Rengo and Nikkeiren as well as their bargaining process de facto engaged the government and the public in a debate on which pay increase Japan could afford; 2) private sector unions and leading companies in export-oriented manufacturing sectors took a lead in shunto discussion; 3) the pay settlements were highly synchronized and this synchronization increased from the mid-1970s; 4) wage settlement norms diffused in an orderly fashion from the private sector to the public sector, from leading pattern setting sectors to followers, from large to small firms, and from corporate headquarters to subsidiaries and affiliates.

Third, the government played a major role as coordinator. It is necessary to distinguish between at least two dimensions. On the one hand, Aoki (2000) convincingly showed that the so-called bureaupluralism contributed to the distribution of the rents within the national economy and established a form of "solidarity" among the sectors. On the other hand, the industrial and innovation policy has played a more offensive role of coordination in selecting the priority sectors and technologies and in promoting R\&D collaboration among firms (Lechevalier, 2006).

\subsubsection{The decay of coordination devices in the Japanese economy}

It is then possible to assess the declining coordination in the Japanese economy, which concerns the three dimensions which have just been distinguished. First, the keiretsu structure has experienced drastic changes since the 1980s, so that it is particularly difficult to recognize the current boundaries of the surviving keiretsu and maybe misleading to use them as a category of analysis (Yamamura and Streeck, 2003). This evolution may have affected the convergence process among firms as explained by Fukao and Kwon (2006): "Until the middle of the 1990s, large firms and many small 
firms were closely tied by sub-contracting and keiretsu relationships and it seems that through this network advanced technologies of assemblers and key-components producers were transferred to lower-tier small suppliers. But as large firms relocated their production abroad and rationalized their procurement processes, this technologytransfer mechanism probably slowed down." This is also true for the subcontracting system, which has become more fluid (Isogai et al., 2000).

Second, the shunto has experienced a profound decay, first in its coverage-more and more companies being not involved in the process-and second in its object-the "bargaining" concerning less and less the increase of wage relative to the productivity gains and more and more general and somewhat vague topics (Boyer and Yamada, 2000). Moreover, the decay of the shunto as a coordination device may be seen through its outcomes. As shown by Sako (2006), in the 1990s, one observed an increasing variation for bonus and wage settlement between roren (network of unions) and within a given roren. As a whole, it is possible to consider that the function of shunto has changed from coordinated pay bargaining to a mechanism for legitimizing pay restraint and dispersion (Sako in Aoki et al., 2007). Last but not least, due to policy mistakes and in a general context of deregulation, both industrial policy and bureaupluralism have experienced drastic changes, if not actual decay (Aoki, 2000; Lechevalier, 2006).

These three evolutions converge towards the decay of non-market coordination devices in the Japanese economy. This is not necessarily a problem, especially if marketbased coordination is efficient or if, for certain reasons, less coordination is needed in the economy. However, many signs converge to show that the market-based coordination mechanisms are not (yet?) functioning efficiently in the contemporary Japanese economy. For example, as shown by Aoki et al. (2007), there is no market for corporate governance. Moreover, the increasing heterogeneity requires more-and not less - coordination than ever. Potentially, a dual or segmented structure is emerging in the Japan of today. It is comparable to the one observed in the 1950s. However, the big difference between these two cases is the existence of coordination devices between the different segments in the 1950s and their absence in the current structure. In our opinion, this is the key for the recovery of the Japanese economy.

\subsection{Towards a new understanding of what was Japanese capitalism and what it has become?}

If this analysis of the Japanese crisis is true, it should lead to a revision of our understanding of the Japanese model. Arguably, this characterization should focus on three dimensions: the decentralization of the model, its evolving differentiated structure, 
and the evolving coordination.

First, the decentralized nature of Japanese capitalism is a key to understanding its current crisis and evolution. It is because he underestimated or even neglected this crucial dimension that Witt (2006) concludes-wrongly, to our opinion-that Japanese capitalism is too closely coordinated. Basically, the major origin of the departure between our approach and the one proposed by Witt is the following. Before being coordinated, Japanese capitalism is highly decentralized in nature. The typology of Calmfors and Driffil (1988) - classifying the Japanese bargaining structure as one of the most decentralized in the world-has been justifiably criticized as missing the key mechanisms of shunto (Sako, 2006). However, it is possible to argue that the shunto has emerged as an essential coordination device because of the fundamentally decentralized nature of the Japanese employment system. The decay of shunto coincides with the increasing diversity of employment conditions in the Japanese labor market. To put it simply, the centralization-decentralization axis is missing in Witt's analysis. In our opinion, it leads to a misunderstanding of the nature of Japanese capitalism. To use Witt's concepts, direct micro-pressures are also important in the case of CMEs, including Japan, and should not be underestimated.

Second, Japanese capitalism should be characterized by a differentiated structure, as argued by Isogai et al. (2000). However, the most important thing here is to recognize that this structure has evolved over time. Basically, it is possible to distinguish between three sub-periods after World War II. In the 1950s and 1960s, the Japanese economy was well characterized by its dualism according to the size of the firm (Shinohara, 1970). This dual structure, which concerns capital intensity, productivity, and wages, has been maintained, but its intensity tended to be reduced, after the turning point of the Japanese economy, at the beginning of the 1960s, when the labor surplus gradually disappeared (Minami, 1994). It led the SMEs to increase wages and therefore to invest more in technology to compensate for the increasing labor cost by an increasing labor productivity. However, progressively, in the 1970s, a new form of heterogeneity, across sectors, became prevalent. This was due to the structural transformation of the Japanese economy, the decline of the sectors which had been the core of the first stages of its development (e.g. textiles) and the progressive building up of new comparative advantages in the machinery sector as a whole. Finally, since the beginning of the 1990s, a new differentiated structure has emerged. At this stage, it is difficult to characterize it through one single dimension. However, it is apparent that it takes place within the usual size and sector categories. While the determination of this new differentiated structure is 
left to further studies, it is worth recalling at this stage that a form of heterogeneity predated the crisis. However, what is new is the considerable increase of this specific form of heterogeneity, labeled "discretionary" by Nelson (1991), to the point that it may be more intense than other forms of heterogeneity. Therefore, this new and increasing form of heterogeneity is not only revealed by the crisis but closely linked to the current institutional changes.

Third, the coordination itself has evolved in the Japanese economy, in its intensity and forms, as was shown above in the analysis of the keiretsu and subcontracting structures, the shunto, and of government intervention in the economy.

To sum up, how can we characterize Japanese capitalism in this framework? This is a form of coordinated capitalism; as is any capitalism, it is characterized by a segmented structure; moreover, its specificity is certainly its highly decentralized nature. Finally, the most important thing is certainly the fact that these three dimensions-coordination, and a differentiated and decentralized structure-are (co)evolving over time. Japanese capitalism during the Lost Decade can be characterized as a highly decentralized, segmented, and uncoordinated form of capitalism. The future of Japanese capitalism lies in the emergence of new and efficient forms of coordination, and this future is still uncertain from this point of view.

\section{The Heterogeneity of Firms: a New Frontier for the Theories of the Variety of Capitalism?}

In this part, we generalize the findings of the previous parts of this article. In doing so, we specify our theoretical framework applied to the analysis of the Japanese economy. After having surveyed the treatment of the heterogeneity of firms by theories of the variety of capitalism and recognized that the evolutionist perspective is the more satisfying from this point of view, we consider successively two limits of this theorythe analysis of the determinants of the heterogeneity, and its normative evaluation. In a final subsection, we specify our concept of coordination by reference to these theories.

\subsection{The variety of capitalism and heterogeneity of firms: the cross of institutional economics?}

\subsubsection{The inability of three institutional theories to deal with the heterogeneity of firms within a national form of capitalism}

What has been found above regarding the inability of theories of the variety of capitalism to analyze the diversity of firms within Japanese capitalism holds for a more general analysis. We consider here the cases of three representative theories, the VOC, 
the CIA (Comparative Institutional Analysis), and the SSP (Social System of Production) approaches.

Despite the influence of the new industrial economics, the VOC approach is unable to conciliate the diversity of national capitalism and the heterogeneity of firms within a given form of capitalism. The main reason is that the VOC approach assumes - for good reasons, in our opinion - that institutional structure conditions corporate strategy (Hall and Soskice, 2001). Consequently, even if it is recognized that structure does not fully determine firm strategy, the room for variations across firms within a national form of capitalism is strictly limited. In fact, the VOC approach emphasizes variations in corporate strategy evident at the national level: differences in the institutional framework of the political economy generate systematic differences in corporate strategy across LMEs and CMEs. More precisely, firms in LMEs invest more extensively in switchable assets, while in CMEs they are more willing to invest in specific or co-specific assets.

The CIA approach is potentially another good candidate to take into account the heterogeneity of firms within one national model. However, what has been seen in the case of the Japanese economy may be generalized as in the following statement by Aoki (2000): "The combined effect of such factors as the bounded rationality of individuals, evolutionary pressures, and institutional complementarity is a tendency for more or less homogeneous organizational convention to be adopted throughout a particular economy. However, different organizational conventions will evolve in different nations." Among these reasons, the evolutionary pressures or the Darwinian process are certainly the most important in Aoki's framework.

The Régulation theory and related frameworks are characterized by similar limitations than the preceding analyses. However, the contribution of the approach in term of social system of production (Boyer and Hollingworth, 1997), which shares with the Regulation theory a number of elements, has to be stressed. The SSP approach manages to emphasize the heterogeneity of firms within countries and sectors by taking into account the characteristics of demand. A basic distinction is between standardized and flexible systems of production. The main novelty by comparison to former approaches is to recognize that it is not uncommon for different components of varying SSP to exist simultaneously in a particular country. For example, even when standardized mass production was the dominant technological paradigm, there were always firms - or even entire industries-that were organized on opposite principles. The two organizing principles were complementary to each other: mass production tended to respond to the stable component of demand, while medium-size production systems tended to cope 
with the variable part of the same demand. This effort to consider the existence of various SP and firms within a national system is a valuable one. However, the argument lacks generality.

\subsubsection{The contribution of an evolutionist approach}

By comparison to these three approaches (VOC, CIA and SSP), the evolutionist theory is certainly the most successful one in combining the variety of capitalism and the diversity of the organization and performance of firms. ${ }^{10)}$ It should first be recalled that the evolutionary approach also contains a theory of the diversity of capitalism (Nelson, 1992). The prevailing institutions - private and public, rival and cooperative - are seen as having evolved through a complex set of processes that involve both individual and collective action. The result is that modern capitalism is a very complex system; that is why there are major differences among the major modern capitalist nations.

Regarding the heterogeneity of firms, the argument starts with the following stylized fact, which can be built from the industrial censuses: different vintages of firms and technologies coexist in most countries over long periods of time. As a result, one observes considerable intra-industry productivity differences among firms in the same industry and in the same country. The theoretical effort to understand this stylized fact then requires going beyond the pure perspective of an economist, to integrate the results from the management science (Nelson, 1991). The economists recognize the differences among firms across sectors or countries. However, they only reflect differences in the contexts in which firms operate. On the other hand, the evolutionist theory is fundamentally interested in discretionary differences across firms. The basic assumption needed to understand this fact is a certain looseness of constraints, both in the short and in the long run, that gives room so that firms that differ in certain important aspects can be viable in the same economic environment. A part of the evolutionist explanation lies in the statement of the considerable variation among firms in the technology they create and adopt and in the large gap between average practice and best practice. Another part of the explanation relates to the considerable range of flexibility left by technology and managerial instructions; that is why the internal organization of the firm matters.

The evolutionist approach is therefore particularly attractive to conciliate the heterogeneity of firms and the diversity of capitalism. However, it is characterized by two drawbacks, which are discussed below: first, the uni-dimensional understanding of the determinants of the heterogeneity of firms, which is itself rooted in a restrictive

${ }^{10)}$ We focus here on a very specific "branch" of the evolutionist approach, the so-called "NeoSchumpeterian" one, which has particularly emphasized the heterogeneity of firms. 
vision of the firm, focusing almost exclusively on technology and innovation; and second, its simplistic normative evaluation of that heterogeneity.

\subsection{Generalizing our understanding of the determinants of the heterogeneity of firms: beyond uni-dimensional technological determinants}

\subsubsection{Preliminary: which theory of the firm?}

\section{An evolutionary theory of the firm}

What is needed in our own framework is a theory not only allowing for the heterogeneity of firms to some extent but one whose major aim is to explain the discretionary firm differences within the same country, the same sector and for firms of similar size. Given this prescription, our theory of firms naturally has an evolutionary flavor. More precisely, we retain two major ideas from various strands of the evolutionary theory of the firm. First, in an environment characterized by a fundamental uncertainty, it is inevitable that firms choose different strategies, which are always some form of experimentation. These choices will then affect their structure (or organization) and their capabilities (Nelson, 1991). Second, if one views the firm as a collection of resources or competences (as in the dynamic capabilities approach), learning becomes important. This cognitive process is partly based on past experience, which implies strong elements of continuity. Moreover, as the most important resources of the firm are the organizational capabilities themselves, which are basically non-transferable, each firm's organization is characterized by important idiosyncrasies (Dosi and Malerba, 1996; Dosi et al., 2000).

\section{Departures from the evolutionist perspective}

These two ideas-the importance of uncertainty and of learning to explain the fundamental heterogeneity of firms - should be nuanced as follows. First, the uncertainty is, of course, influenced by business cycles (and market perspectives) and by technological changes. But these are not the only two elements of uncertainty that each firm has to face. In a changing institutional and legal environment, the domains and scope of strategic and organizational choices a firm has to make tend to widen. For example, in a context of financial deregulation and increasing openness, the range of possibilities for each firm is increasing, and the choices to be made are not without consequences. Second, the learning and the capabilities do not concern only innovation. A fundamental departure of our perspective with the evolutionary approach is that we include the choice of technology and more generally innovation as an essential part of the firm's strategy, but not as the key to everything. To put it simply, in our view, the evolutionist approach tends to overemphasize the importance of technology and 
innovation. It is true that this is capital in some high-tech sectors. It is also true that each firm innovates, in one way or another, not only in spending specific resources for R\&D. However, before technology and innovation, most of the firms have first to make decisions regarding other dimensions of their organization and strategy. Moreover, even if one should not restrict the innovation to $R \& D$, it is important to recall that, for example, the practice of R\&D concerns only a minority of Japanese firms. ${ }^{11)}$

\section{From the five dimensions of the organization and strategy of firms to the definition of models}

As a whole, we can distinguish five dimensions of the organization and strategy of firms, for which choices will be the root of their heterogeneity. Three of them concern specifically organization: these are the diversification of products and the organizational structure, human resource management, and corporate finance and governance. Two are related to what one could call the strategy level: these are innovation and internationalization. Strategy is distinguished here from organization, as innovation and internationalization are in a sense "optional." In particular, contrary to what is postulated by the evolutionist approach, innovation is not the essence of the behavior of firms. This essence is better defined by the production of goods and services through the mobilization of diverse resources. In this sense, investment-and the associated capital accumulation - is the "degree zero" of the activity of firms. Of course, at the same time, the resulting supply is expected to meet a demand. This is the locus of the first logical dimension of the organization of firms: the degree of diversification of products and the type of organizational structure. The firm has indeed first to choose what kind of goods or services it will produce or deliver. This choice has a direct impact on its internal organizational structure. However, for a given diversification, the firm still has a certain degree of freedom to choose its organizational structure (e.g., form and number of divisions). Human resource management and corporate finance and governance are the two following dimensions of the organization of firms: Aoki (1989) convincingly showed how the choices for these two dimensions are a primary source of differentiation of the organization of firms.

In our framework, innovation logically comes in fourth position to characterize the choices that each firm has to make. At the same time, it is the first dimension of a firm's strategy. As well shown by the evolutionist literature, it is even capital for the development of the dynamic capabilities of firms. Finally, internationalization is the

\footnotetext{
${ }^{11)}$ According to Kiyota (2006), 70\% of Japanese manufacturing firms did not declare any R\&D expenses between 1995 and 2002.
} 
second dimension of the strategy of firms (and therefore the fifth characteristic of each firm's model). As innovation, it concerns only a minority of firms, mainly (but not exclusively) the manufacturing firms. ${ }^{12)}$ The choice of internationalization has become relatively recently a key dimension of the strategy of firms - and not only for the large multinationals - in the context of globalization. It is basically related to the choices of export and/or FDI.

These five dimensions are integral parts of the organization and strategy of firms. However, are they exhaustive? More specifically, we did not include another potential candidate: the relations with other institutions and organizations, namely, with other firms and with the government. It is de facto an essential part of a firm's strategy. However, we did not select it for at least three reasons. First, it is already partly included in the five dimensions distinguished above: for example, the decision to do joint research with another company or to participate in government-sponsored research consortia is a part of innovation strategy. Second, it concerns by definition what is external to the firm, while the five other dimensions are more "internal." Last, but not least, it occupies a specific place in our framework and operates at a different level, which will be defined below as the coordination level.

In a second step, the nature of a firm's organization and strategy is defined by the complementarities between the five dimensions distinguished above. It is precisely at this level, which implies coherence, that heterogeneity fundamentally takes place, even if, of course, some heterogeneity appears for each dimension of the organization and strategy of firms.

\subsubsection{Converging and diverging forces: the determinants of the evolution of the heterogeneity of firms}

In direct relation with our departure from the evolutionist theory of the firm, because of its almost exclusive focus on technology and innovation, our analysis of the converging and diverging forces at work in the economy also has distinctive features. The understanding of these forces is essential in our framework because their net effect leads to a more or less intense heterogeneity across firms. Our assumption is that these forces are not limited to technology and that they vary across countries and industries and over time.

Basically, according to the evolutionist theory, the driving force of the heterogeneity of firms is technology. On one side, innovation is a powerful diverging force, while, on

${ }^{12)}$ For example, in the case of Japan, Kimura \& Kiyota (2006) show that $76 \%$ of firms were "domestic" (neither export nor FDI) between 1994 and 2000. 
the other, diffusion is an efficient converging force. Without neglecting the influence of technology on the heterogeneity of firms, our framework aims at introducing other factors. One is related to macroeconomic and industrial cycles. The level of activity obviously has an impact on heterogeneity, even if the net impact is rather ambiguous.

More importantly, our perspective focuses particularly on the institutional determinants of heterogeneity. The most obvious is the degree of internationalization of the national economy. As seen in the Japanese case, deregulation, particularly in the financial sphere, is also an important determinant of the overall heterogeneity, as it affects the number of possible choices that the firms are facing. Last but not least, the forms and intensity of coordination in the economy affect the heterogeneity of firms.

Based on this analysis of converging/diverging forces, it is possible to answer the question of the specificity of the Japanese trajectory from the point of view of increasing heterogeneity. If the forces at work are basically technological, the trend toward increasing heterogeneity may be expected to be general and not limited to Japan. On the other hand, if certain institutional factors matter (e.g. deregulation, mode of reform), it becomes understandable that each country may follow a specific path. Without neglecting the importance of technology, our own analysis tends to focus on these institutional determinants and therefore on the inter-country differences. ${ }^{13)}$

\subsection{Normative evaluations of the heterogeneity of firms: its impact on inequalities and on the macro-performance of countries}

A second departure from the evolutionist approach concerns the normative evaluation of heterogeneity. We focus here on the question of the economics gains of the diversity of organizations. ${ }^{14)}$ We can distinguish here two arguments, respectively from static and dynamic perspectives.

The basis of the reasoning concerning the potential static gains of organizational diversity can be summarized as follows (Aoki, 2000). A particular organizational mode will not be the most efficient mode in all industries. The best possible option would be to have a pluralistic economy in which different organizational modes are selected in accordance with the particular market and technological environments facing each industry. That is why economies with institutional structures that tolerate the entrance of

${ }^{13)}$ Our research can therefore be considered as a generalization of the perspective by Katz and Darbishire (1999), who focus on human resource management. According to their results, the increasing heterogeneity of employment systems within a country is a general phenomenon common to different countries; however, it varies across countries (e.g., from high in the US to low in Germany).

${ }^{14)}$ We do not mention here the negative impact of heterogeneity on inequalities (Oï, 1983). 
experimental organizations are likely to perform better than others.

As for the dynamic-type argument, it takes more or less the following form (Nelson, 1991). The diversity of technology and organization plays a positive role in providing flexibility and adaptability. Some losses in static efficiency (the average firm is far from the best practice) might be overcome by the gain in dynamic efficiency, due to the variety of alternative technologies and organizations that could be developed as firms constantly face new environments.

Both arguments are partially true but they are over-optimistic. They share what we consider as a common illusion, based on a natural science metaphor. Although the concept of a Darwinian selection process applies very convincingly to the diversities of natural species, it should be used very carefully in the case of organizations and, especially, firms. Beyond this very general criticism, we would like to emphasize here a common limit shared by the two arguments: the underestimation of the problem of coordination related to the heterogeneity of firms. The large-scale heterogeneity of firms is not always a guarantee for growth. If organizational diversity is beneficial for the exploration of potential new opportunities, it raises issues regarding the selection of the various paths and the diffusion of organizational innovations. For example, in the case of technology, spillovers are not automatic; coordination is required. The final section of this paper is devoted to the development of our concept of coordination.

\subsection{Reconsidering the link between the heterogeneity of firms and macro-performance: why coordination matters}

\subsubsection{The theoretical foundation of the concept of coordination}

In our framework, the source of the coordination problem is neither the division of labor nor the structure of the game, but rather the fundamental heterogeneity of firms. Our concept of coordination is directly related to the existence of heterogeneity at the microlevel. In a world with only identical agents, the aggregation of micro behaviors and the coordination of potential complementarities do not raise any specific issue. To put it simply, there is no need of specific coordination beyond a pure market approach. On the contrary, in a world with heterogeneous agents, aggregation and coordination are problematic. First, there is no simple solution to the aggregation of heterogeneous agents (Aoki and Yoshikawa, 2006). Second, there is a priori still a place for coordination through markets. However, as it appears in the tradition of the General Equilibrium, markets loose their comparative advantage from the point of view of coordination as soon as the agents are no more identical. Third, if complementarities between heterogeneous organizations are potentially higher than between homogenous agents, 
they are not automatic. Therefore, a specific coordination is required.

The theoretical interest of this concept lies in analyzing the interaction between the macro and the micro levels. It is not about the allocation issue. It is rather about the interaction between heterogeneous agents and the aggregation of their behaviors and performances. Another characteristic is that coordination takes place in a decentralized environment. It is precisely because of this decentralization that coordination is required, as shown in the case of Japanese capitalism, whose coordinated structure cannot be understood without its decentralized nature.

Our main source of inspiration comes from the tradition of mathematical economics, which criticizes the neo-classical hypothesis of the representative agents and proposes an alternative framework to consider the aggregation of heterogeneous agents (Kirman and Zimmermann, 2001; Cowan and Jonard, 2003). In fact, the inability to consider the heterogeneity of firms within a given form of capitalism by theories of the diversity of capitalism (with the exception of the evolutionist approach) comes from the same drawback as that in the neo-classical framework, the assumed existence of a representative agent in each form of capitalism. In this context, a drastic change is required, a change of the same scale as the one proposed by Aoki and Yoshikawa (2006) in the case of a more standard macroeconomic approach. The issue at stake is indeed to propose a new foundation of institutional economics, based on the heterogeneity of firms.

\subsubsection{Specifying the concept of coordination}

As can be seen through its theoretical foundation, the coordination issue that we emphasize is located not within organizations but among them. It takes basically two forms, the coordination among firms and the coordination pursued by the government. Therefore, coordination does not mean government intervention. Moreover, among-firms coordination is a private form of coordination but is outside the scope of market coordination. It means that this concept of coordination goes beyond the dichotomy between State and markets. Moreover, this is a macro concept. However, as shown through the example of inter-firm coordination, it can also be thought as operating at a meso level. On the whole, coordination is located at the aggregate level.

This also means that coordination is an institutionalist concept, even if its inspiration comes from mathematical economics. Examples of coordination devices have been given in the Japanese case: these are the shunto, the keiretsu and subcontracting structures, or industrial policy. As can be seen through these examples, an area where coordination is particularly important concerns the spread of technological innovation. More precisely, 
such forms of interaction, like externalities or spillovers, are not automatic and require a range of coordination devices to be effective. However, diffusion of innovation is not the only field where coordination is necessary, as is apparent through the example of shunto. Therefore, in this framework, from a functionalist point of view, institutions are seen as coordinating mechanisms. These mechanisms differ in each form of capitalism, which is defined not by the particular set of institutions but rather by the mode of coordination.

This concept of coordination is associated with a specific concept of equilibrium, very similar to the one developed by Aoki and Yoshikawa (2006): equilibrium should not be thought of as a deterministic point but rather as a probability distribution over a set of points. For example, this equilibrium is characterized by a number of productivity levels rather than a unique level of productivity: productivities across firms do not equalize. However, coordination is not only static but also allows consideration of the different dimensions and levels of institutional change. As the heterogeneity of firms evolves, institutional change takes place at the micro level, through the impact of macro factors like technological change, business cycles, and changes in the institutions, whose effect is mediated through the choices of individual actors (e.g., entrepreneurs). Institutional change also takes place at the macro level, through the evolving coordination devices. To summarize, coordination has a double dimension. At a given level of heterogeneity, it defines the conditions of the micro-macro interaction. But it also influences the evolution of heterogeneity at the firm level, as one of its determinants.

Finally, it is worth emphasizing that this concept of coordination is definitively on the "constructivist" side. Despite their critical differences regarding the homogeneity/ heterogeneity of agents, the conditions of aggregation, and the understanding of dynamics, the standard and the evolutionist approaches share the idea of the existence of a "spontaneous order." More precisely, in a context of micro heterogeneity and of evolutionary technical change, the evolutionist approach needs some kind of selforganization to produce an order. Therefore, it is not surprising that Dosi et al. (1988) use the metaphor of an "Evolutionary Hand" to explain the production of this order in a very similar way to the famous "Invisible Hand" required in a standard approach to explain the functioning of the markets. On the other hand, our concept of coordination has nothing to do with a "natural order." This is a purely institutional and political construction, even if it is fair to recognize that the effects of the various coordination devices largely go beyond what is often expected or thought of by the actors themselves.

Therefore, it is possible to stress the political dimension of this concept of coordination. It is first worth recalling the criticisms by Amable (2003) regarding the 
"economicist" or "rational choice" view of institutions: according to this perspective, institutions emerge spontaneously and unintentionally out of individual interactions. On the contrary, Amable argues, institutional design reflects conflict over distributional issues; in this context, individual interactions lead to institutional equilibriums reflecting power asymmetries and conflict of interests. Institutions are not primarily designed to solve coordination problems between equal agents with similar interests, but to solve conflict among unequal actors with divergent interests. In our opinion, the concept of coordination developed in this paper "escapes" from these criticisms. First, focusing on the heterogeneity of players, we allow for the introduction of unequal characteristics. Second, coordination by itself is often a way to redistribute across different types of organization as distinguished according to their efficiency, as appears in our interpretation of dualism in Japan and in the concept of "bureaupluralism" developed by Aoki. Finally, it is worth referring to the argument developed by Gourevitch (1996): the microstructure of industries and firms has a substantial impact on the performances of economies and should be an essential object of study in comparative capitalism; these microstructures are shaped by regulatory policies, which themselves arise from political processes in each country. In other words, the coordination issue is also highly political. ${ }^{15)}$

\subsubsection{Evolving heterogeneity of firms and coordination: towards a more dynamic understanding of institutional change?}

Finally, it is important to compare our framework with some recent attempts to provide a more dynamic view on the institutional change. In particular, the purpose is to analyze an incremental but transformational change (Streeck and Thelen, 2005). This type of change seems to be characteristic of the secular expansion of market relations that most advanced economies experienced since the 1980s-1990s, which is labeled as liberalization by Streeck and Thelen (2005). The approach followed by these authors is essentially based on a less deterministic view of institutions: they are less seen as incentives and constraints than as resources for actions, which in turn may incrementally transform them. Deeg and Jackson (2006) also follow this route, in adding a distinction between three levels of analysis, the micro, meso, and macro levels.

Our own framework is sympathetic to this resource-view of institutions and to this distinction between various levels of analysis. Its specificity and expected contribution is

\footnotetext{
${ }^{15)}$ Although he convincingly developed an approach, in which coordination and power issues are jointly analyzed, we do not refer here to Bowles (2004), because his concept of coordination is based on a game theory approach and is therefore clearly distinct from ours.
} 
to distinguish between two levels of change-the organizational change (at the micro level) and the institutional change (at the aggregate level)-and to articulate them through the concept of coordination, which define the conditions of aggregation. We argue that it is not possible to understand institutional change (especially the type of incremental institutional change) without an appropriate micro-foundation, which should lie on the analysis of the evolution of the heterogeneity of firms. This is the stage of the analysis of the organizational change, for which an appropriate theory of the firm is required, as discussed in the paragraph 3.2.

At the micro level, everything is not shaped by the institutional environment. There is room for change, which will contribute in turn to the institutional change. Therefore, we can understand the possibility of diverging changes at the micro level (eventually leading to an apparent stability at the aggregate level). Nothing implies that organizational change goes through the same direction for each firm, even if the diverging process at the firm level is not purely random: it is made also possible by different initial conditions and incentives. More importantly, the diverging choices at the firm level in term of organization (i.e. the increasing heterogeneity of firms) can be explained by the broader range of possibilities, which emerged in a more opened environment, created by deregulation or liberalization. The long process of deregulation in countries like Germany and Japan did not create the expected changes, like a simple shift towards the A model. More deeply, it has given more opportunities to firms to choose a specific strategy. It means that the observed organizational change is the result of the intermediation by organizations of the changes in the environment (institutional change 1 or IC1, which is itself the complex result of previous evolution), leading to changes at the aggregate level (institutional change 2, or IC2), in an unexpected form by comparison to the initial change (IC1), and at the condition that a certain critical mass is reached.

To summarize our argument: the resulting institutional change fundamentally depends on its mediation by firms and on the evolving composition of the economy in terms of "models" at the firm level. However, this relation between the composition of the economy and the institutional change is characterized by important non-linearities and is therefore far from being mechanical. The concept of coordination provides a tool to analyze the complex process of dynamic aggregation and of articulation between the micro and the aggregate levels of change. 


\section{Conclusion}

Through a case study of the Japanese economy during the Lost Decade (1992-2005), we have argued in this paper that the implicit assumption of the existence of a representative firm in each national form of capitalism introduces severe drawbacks in the analysis of the variety of capitalism, especially regarding the institutional change.

Taking into account the increasing heterogeneity of Japanese firms during the Lost Decade leads us to propose an alternative interpretation of the Japanese crisis as a lack of coordination of this heterogeneity: the increasing heterogeneity of Japanese firms had a negative impact in term of performance, in a context of the decay of private and public coordination devices. In turn, this leads us to revise our understanding of what has been and what is the Japanese model. Its coordinated nature is not enough to characterize it. Its decentralized and differentiated structures are also two key elements. Finally, not taking into account the fact that these three characteristics are evolving over time leads to a misunderstanding of the organizational and institutional changes in the Japanese economy.

The novelty of the perspective proposed in this paper can be summarized as follows. It provides an analysis of the institutional change that has affected the Japanese economy since the 1980s rather than a theory of the causes of the crisis: the increasing heterogeneity cannot be reduced to the crisis. More generally, if the heterogeneity of firms is obvious, especially from an evolutionist perspective, its evolution over time and the differences across national economies from this respect are not. This leads us to define a double research agenda.

In the 1980s and the early 1990s, the research agenda to analyze the specificities of Japanese capitalism has consisted of comparisons with American capitalism. It has led to a better understanding of both forms of capitalism, even if a more systematic comparison with Europe would have been desirable. The present paper is a call for a renewal of studies on Japanese capitalism. The idea is not to give up systematic international comparisons at the aggregate level but to focus on the diversity of firms within the Japanese form of capitalism. Another object of research which emerged from this paper is the analysis of new lines of segmentation within the Japanese economy. If size and industry obviously matter, they are not enough to understand the dynamic of Japanese firms and of Japanese capitalism. Further research should assess the new differentiated structure of the Japanese economy.

Finally, beyond the Japanese case, this paper aims at promoting a new research agenda for the institutional approach of comparisons of capitalism, providing a systematic 
analysis of the heterogeneity of firms within each form of capitalism. The Japanese case is certainly not unique, even if it is too early to characterize the current trend experienced by forms of capitalism as "converging divergences" (Katz and Darbishire, 1999). It is therefore important to analyze carefully each form of capitalism from this point of view. The theories of the diversity of capitalism have tended so far to neglect intra-country differences to emphasize inter-country differences. If an evolutionist approach is a priori better equipped than others, because of its focus on "discretionary" heterogeneity across firms, to realize this research agenda, it has two important limitations: its exaggerated emphasis of technology in its theory of the firm and in its analysis of the determinants of micro heterogeneity; and its simplistic normative evaluation of the heterogeneity of firms as the engine of growth. Any institutional comparative analysis of capitalism should be based on a more complete theory of the firm and on the idea that the impact of micro heterogeneity on macro performance fundamentally depends on the quality of coordination at the aggregate level. More generally, to understand institutional change in a more dynamic way, it is important to analyze organizational change at the micro level and the conditions of its aggregation.

\section{References}

Aghion, P. and G. Saint-Paul (1991) On the virtues of bad times: an analysis of the interaction between fluctuations and economic growth, CEPR Working Paper $n^{\circ} 578$.

Amable, B. (2003) The Diversity of Modern Capitalism, Oxford University Press.

Aoki, M. (1986) "Horizontal versus Vertical Information Structure of the Firm," The American Economic Review 76. 5: 971-983.

(1989) "The Nature of the Japanese Firm as a Nexus of Employment and Financial Contracts: An Overview," Journal of the Japanese and International Economies 3.4: 345-366.

- (1990) "Toward an Economic Model of the Japanese Firm," Journal of Economic Literature 28: 1-27.

- (2000) Information, Corporate Governance, and Institutional Diversity. Competitiveness in Japan, the USA, and the Transitional Economies, Oxford University Press.

—, G. Jackson and H. Miyajima (2007) Corporate Governance In Japan. Institutional Change And Organizational Diversity, Oxford University Press.

and H. Yoshikawa (2006) Reconstructing Macroeconomics: a Perspective From Statistical Physics And Combinatorial Stochastic Processes, Cambridge University Press.

Bowles, S. (2004) Microeconomics: behavior, institutions, and evolution, Russell Sage Foundation, Princeton; Princeton University Press, Oxford (The roundtable series in 
behavioral economics).

Boyer, R. and J. R. Hollingsworth (1997) "Coordination of Economic Actors and Social Systems of Production," in R. Boyer and J. R. Hollingsworth (eds) Contemporary Capitalism. The Embeddedness of Institutions, Cambridge University Press.

- and T. Yamada (eds) (2000) Japanese Capitalism in Crisis. A regulationist interpretation, Routledge.

Calmfors, L. and J. Driffill (1988) "Bargaining Structure, Corporatism, and Macroeconomic Performance," Economic Policy 3. 6: 13-61.

Cowan, R. and N. Jonard (eds) (2003) Heterogeneous Agents, Interactions and Economic Performance, Lectures Notes in Economics, Lectures Notes in Economics and Mathematical Systems $n^{\circ}$ 503, Springer Verlag.

Deeg, R. and G. Jackson (2006) Towards a More Dynamic Theory of Capitalist Variety, King's College London-Department of Management Research papers Number 40.

Dosi, G. and F. Malerba (eds) (1996) Organization and Strategy in the Evolution of the Enterprise, MacMillan Press.

— C. Freeman, R. R. Nelson, G. Silverberg and L. Soete (1988) Technical Change and Economic Theory, Pinter Publishers.

—_, R. R. Nelson and S. G. Winter (eds) (2000) The Nature and Dynamics of Organizational Capabilities, Oxford University Press, Oxford.

Freyssenet, M., A. Mair, K. Shimizu, G. Volpato (eds) (1998) One Best Way? Trajectories and Industrial Models of the World's Automobile Producers, Oxford University Press, Oxford.

Fujimoto, T. (1999) The Evolution of a Manufacturing System at Toyota, Oxford University Press, Oxford.

Fukao, K. and H. U. Kwon (2006) "Why did Japan's TFP Growth Slow Down in the Lost Decade? An Empirical Analysis Based on Firm-Level Data of Manufacturing Firms," Japanese Economic Review 57: 195-228.

Gourevitch, P. (1996) "The Macropolitics of Microinstitutional Differences in the Analysis of Comparative Capitalism," in S. Berger and R. Dore (eds) National Diversity and Global Capitalism, Cornell University Press.

Hall, R. and D. Soskice (eds) (2001) Varieties of Capitalism: the Institutional Foundations of Comparative Advantage, Oxford University Press.

Hurlin, C. and S. Lechevalier (2003) The Heterogeneity of Employment Adjustment across Japanese Firms. A Study using Panel Data, Couverture orange du CEPREMAP n ${ }^{2003-}$ 10.

Isogai, A., A. Ebizuka and H. Uemura (2000) "The Hierarchical market-firm nexus as the Japanese mode of Regulation," in R. Boyer and T. Yamada (eds) Japanese Capitalism in Crisis. A regulationist interpretation, Routledge.

Ito, K. and S. Lechevalier (2007) The productivity heterogeneity of Japanese firms during the 
Lost Decade. Did it increase? Why?, RIETI Discussion paper (forthcoming).

Jackson, G. (2003) "Corporate Governance in Germany and Japan: Liberalization Pressures and Responses during the 1990s," in K. Yamamura and W. Streeck (eds) The End of Diversity? Prospects for German and Japanese Capitalism, Cornell University Press.

Katz, H. and O. Darbishire (1999) Converging Divergences. Worldwide Changes in Employment Systems, Cornell University Press.

Kiyota, K. (2006) Reconsidering the Effects of Intranational and International R\&D Spillovers on Productivity Growth: Firm-level Evidence from Japan, RIETI Discussion Paper Series 06-E-001.

and T. Okazaki (2005) "Foreign Technology Acquisition Policy and Firm Performance in Japan, 1957-1970: Micro-aspects of Industrial Policy," International Journal of Industrial Organization 23. 7-8: 563-586.

Kirman, A. and J.-B. Zimmermann (eds) (2001) Economics with Heterogeneous Interacting Agents, Lectures Notes in Economics, Lectures Notes in Economics and Mathematical Systems $n^{\circ}$ 503, Springer Verlag.

Lechevalier, S. (2007) Heterogeneity of firms and coordination. An alternative interpretation of the Lost Decade in Japan and a research agenda for theories of the diversity of capitalism, IER Discussion paper, Hitotsubashi University (forthcoming).

- (2006) Recent Changes in the Japanese Public Research and Innovation PoliciesLessons for Europe, Research Project undertaken for the European Union (Delegation of the European Commission to Japan, Tokyo, June.)

Lincoln, J. R. and M. L. Gerlach (2004) Japan's network economy: structure, persistence, and change, Cambridge University Press.

Minami, R. (1994) The Economic Development of Japan. A Quantitative Study, St Martin Press.

Nakamura, J. (2002) "Microstructure of persistent ROA decline in the Japanese corporate sector: Inter-company disparities and investment strategies," Development Bank of Japan Research Report No. 23, March.

Nelson, R. R. (1981) "Research on Productivity Growth and Productivity Differences: Dead Ends and New Departures," Journal of Economic Literature 19. 3: 1029-1064.

- (1991) "Why Do Firms Differ, And How Does it Matter?," Strategic Management Journal 12: 61-74.

- (1992) National innovation systems: a comparative analysis, Oxford University Press.

Nishiguchi, T. (1994) Strategic Industrial Sourcing: The Japanese Advantage, Oxford University Press.

Nishimura, K. G., T. Nakajima and K. Kiyota (2005) "Does Natural Selection Mechanism Still Work in Severe Recession? Examination of the Japanese Economy in the 1990s," Journal of Economic Behavior and Organization 58. 1: 53-78.

Odagiri, H. (1994) Growth through competition. Competition through growth, Clarendon Press 
Oxford.

Sako, M. (2006) Shifting Boundaries of the Firm. Japanese Company-Japanese Labor, Oxford University Press. and H. Sato (1997) Japanese Labor and Management in Transition, Routledge.

Shinohara, M. (1970) "Structural changes in Japan's Economic Development," Economic Research Series 11 (The Institute of Economic Research, Hitotsubashi University), Kinokuniya.

Streeck, W. and K. Thelen (eds) (2005) Beyond Continuity. Institutional Change in Advanced Political Economies, Oxford University Press.

- and K. Yamamura (eds) (2001) The Origins of Nonliberal Capitalism, Cornell University Press.

Suzuki, K. (1993) "R\&D Spillovers and technology transfer among and within vertical keiretsu groups. Evidence from the Japanese electrical machinery industry," International Journal of Industrial Organization 11: 573-591.

Vogel, S. (2006) Japan Remodeled: How Government and Industry Are Reforming Japanese Capitalism, Cornell University Press.

- (2005) "Routine Adjustment and Bounded Innovation: the Changing Political Economy of Japan," in W. Streeck and K. Thelen (eds) Beyond Continuity. Institutional Change in Advanced Political Economies, Oxford University Press.

Walter, Y. Oi (1983) "Heterogeneous Firms and the Organization of Production," Economic Inquiry 21. 2: 147-171.

Witt, M. A. (2006) Changing Japanese Capitalism. Societal Coordination and Institutional Adjustment, Cambridge University Press.

Yamamura, K. and W. Streeck (eds) (2003) The End of Diversity? Prospects for German and Japanese Capitalism, Cornell University Press. 